\title{
Bankruptcy Risk Assessment in Corporate Lending Based on Hybrid Neural Networks and Fuzzy Models
}

\author{
Stanislav Gorbatkov \\ Doctor of Engineering Sciences, Professor, Honored Scientist of the Republic of Bashkortostan \\ E-mail: sgorbatkov@mail.ru \\ $\underline{\text { ORCID }}$
}

Department of Mathematics and Informatics, Financial University under the Government of the Russian Federation, Ufa, Russia

\section{Svetlana Farkhieva}

Candidate of Engineering Sciences (PhD), Head of the Department of Mathematics and Informatics E-mail: ok-xi@yandex.ru

$\underline{\text { ORCID }}$

Department of Mathematics and Informatics, Financial University under the Government of the Russian Federation, Ufa, Russia

Journal of Corporate Finance Research, Vol. 13, No. 1, pp. 28-39 (2019)

DOI: https://doi.org/10.17323/j.jcfr.2073-0438.13.1.2019.28-39

Received 18 January 2019 | Peer-reviewed 10 February 2019 | Accepted 5 March 2019 


\section{Bankruptcy Risk Assessment in Corporate Lending Based on Hybrid Neural Networks and Fuzzy Models}

\section{Abstract}

The purpose of this article is the presentation of a novel and unconventional algorithm for bankruptcy risk management in banking technologies catered towards lending to legal entities (enterprises and companies). The challenges of assessing risk in this area primarily relate to the reduction of type I and type II errors when making decisions on the terms of lending (i.e. loan amounts and repayment parameters) on the ostensibly objective basis of a borrower's creditworthiness assessment.

As such, it is necessary to use a unified procedure to select appropriate economic indicators for any bankruptcy model in order to reduce the high degree of uncertainty and noisiness of publicly available databases, and to take into consideration the specific character of knowledge-intensive, high-tech and "green" manufacturing. In order to approach this challenge, a mix of various methods is presented in this article, including credit scoring, neural simulation, a fuzzy model description, fuzzy inference rules, and a fuzzy Pospelov scale.

The research results are as follows: the authors have developed an unconventional algorithm for diagnosing corporate bankruptcy stages. This algorithm is based on the application of a system-wide law relating to decreases in integrated system entropy, contrasted with the sum of entropies of the relevant collated subsystems. This algorithm has been tested on a series of experimental observations of 30 agricultural enterprises in the Sterlitamak District of the Republic of Bashkortostan. We have thusly assessed the financial condition of borrowing companies, while controlling for the probability of a wide range of indicators.

Using this algorithm, the authors decided not to apply the rigorous requirements of the classical 'least squares' method used in regression analyses. A switch to a neural simulation approach in this algorithm necessitated an evaluation of the adequacy of the obtained model on the basis of a Bayesian approach. On the basis of this research, the authors propose that a regularisation of bankruptcy models has been achieved.

Keywords: eype I and II errors, lending risks, scoring models, neural network, fuzzy Pospelov pentascale JEL classification: C45, C58, G17, G33 


\section{Introduction}

In loan transactions and subsequent operations (e.g. loan restructuring and management), if a legal entity is unable to repay the whole amount of the loan within the period stipulated in the agreement, accurate information regarding the stages of the borrower's potential bankruptcy may be of great importance. Such information could be obtained from mathematical bankruptcy models developed on the basis of standard accounting reports. Here one encounters the following problems:

1) an absence of a common or unified method of economic indicator (factors) selection for the bankruptcy model;

2) a high degree of uncertainty and noisiness in publicly available databases, preconditioned by the fact that in some cases it is to the borrower's advantage to "paint in bright colours" its financial and economic performance in the standard accounting reports (such unreliable databases are described by some model builders with reference to an "in-factors triad": that is, the presence of incertitude, inaccuracy, and incompleteness);

3) due to the rapid development of knowledgeintensive, high-tech and "green" manufacturing, the engineering and financial/economic processes of various enterprises acquire a specific corporate character which may prove useful in the identification of the company's status. This character is not fully described in the accounting standards, which can account for the development of the conditions where the abovementioned in-factors triad is characteristic of the available data.

In view of the above problems, the authors are motivated to develop suitable procedures to help solve the problems in assessment of bankruptcy risk for corporations and companies in Russia as well as abroad. Three primary approaches towards this development are described in the present article:

1) The integration of various methodological approaches into one algorithm, which, in accordance with the system-wide law of integrated system entropy decrease (resulting from the integration of interacting subsystems) initiates an emergent effect which improves algorithm [1]:

$I\left(A_{1}, A_{2}\right)-I\left(A_{1}\right)-I\left(A_{2}\right)=\Delta I\left(A_{1}, A_{2}\right)>0$,

where $A_{1}, A_{2}$ refer to subsystems to be integrated; $I\left(A_{1}\right)$, $\mathrm{I}\left(\mathrm{A}_{2}\right)$ refer to the entropy of isolated subsystems which do not exchange information and material flow; $I\left(A_{1}, A_{2}\right)$ represents the entropy of an integrated system which is less than the sum of entropies of subsystems $A_{1}, A_{2}$ as a result emergence of additional links, and hence a reduction of the number of acceptable states of the integrated system $\left(A_{1}, A_{2}\right)$; and $\Delta I\left(A_{1}, A_{2}\right)$ refers to useful information generated by integration (negentropy). The addition of such useful a priori information facilitates narrowing the scope of the search for solutions of ill-conditioned inverse problems of data interpretation (approximation), and hence the sought-after regularisation in approach [2].

2) The introduction in the bankruptcy model of qualitative factors along with quantitative ones, for example, on the basis of a fuzzy model methodology, and inference rules $[3,4]$.

3) The presence of attempts to assess the stages of advancing crisis in the bankruptcy model for companies and corporations and, when possible, attempts to make a time forecast of the bankruptcy stages for a specific instant in time $t_{0}$. The term "when possible" is used here because dynamic bankruptcy models with a continuous time variable $t$ have not yet been developed in practice.

We know two method groups which, according to one effectiveness measure or another (e.g. by reference to the share of type I or type II errors in the bankruptcy risk assessment), prove to be functional in the model in trying circumstances of model building described above. These groups are:

- fuzzy model description and fuzzy inference rules methods;

- neural simulation methods.

The present article generalises and develops bankruptcy models [1] on the basis of the system law of entropy balance exemplified by correlation (1), and offers an unconventional algorithm by combining the neural network method for bankruptcy prediction with a fuzzy bankruptcy stage assessment method.

\section{Review of Literature}

W.Beaver [5] is considered to have provided the foundation research in this particular area. He was looking for a way to create a unique methodology for bankruptcy risk assessment on the basis of companies' financial indicators. The basic premise of his research in this sphere was the idea that company insolvency may be assessed on the basis of the cash flow model.

From the beginning, Beaver's method comprised an analysis of 14 indicators, but eventually the list was shortened to the following six:

- ratio of cash flow to the total debt amount;

- liquidity ratio;

- ratio of net profit to total assets;

- ratio of liabilities to total assets;

- ratio of working capital to total assets;

- the difference between current assets and liabilities.

By comparing values obtained for companies which have undergone bankruptcy procedures and those which have not faced financial difficulties, Beaver identified the following regularity: for five years before bankruptcy, the mean values of the above six indicators declined significantly in subcritical companies, while they have stayed unchanged in reliable companies. 
Bayes also identified the optimal values for each parameter he studied by minimising type I and II errors. Thus, in his approach, the indicators of a particular company are compared to guideline values and a conclusion is made on the enterprise's financial stability and bankruptcy probability in various time horizons (e.g. between one year and five years).

It should be noted that this method holds a unique position in the financial science, as Beaver was among the first to offer an accessible approach to the use of financial indicators for bankruptcy prediction. Not least among the benefits of this approach are its simplicity, and the fact that by using it the author managed to correctly predict bankruptcy in $78 \%$ of cases.

However, a range of restrictions in such an approach should also be noted. First, the indicators in various countries and industries may differ distinctly, as well as the indicators for the companies at different life cycle stages. Second, some indicators may be of more importance than others when predicting bankruptcy, depending of course on the individual company.

E. Altman [6] improved Beaver's approach. He applied a multivariate discriminant analysis to a selection of industrial companies, half of which had undergone bankruptcy procedures. Consequently, when comparing the values of the selected indicators for sub-selections, Altman obtained critical values which may be used to place a company into one or another risk group.

According to Altman's methodology the main indicators that influence bankruptcy are as follows:

- ratio of working capital to total assets;

- ratio of undistributed profits to total assets;

- ratio of operating income to total assets;

- share of the market value of equity in the overall liabilities;

- ratio of revenue to total assets.

In Altman's approach, each indicator is assigned a certain value which is included in the general assessment (Z-score) of a company's financial standing. On the basis of the absolute value of the obtained assessment, a conclusion is made about the company's reliability. The results of E. Altman's approach turned out to be more impressive in comparison with Beaver's method, because it was revealed to predict bankruptcy in $90 \%$ of cases.

The drawback of this approach is that it is difficult to apply it to companies whose shares are not quoted on securities markets, as well as for companies from non-production sectors. It should, however, be noted that later Altman developed a modification of the initial model which helped to assess bankruptcy probability for non-public companies and non-production enterprises.

E. Deakin [7] offered to combine Beaver's and Altman's approaches. He analysed a series of British companies which had undergone bankruptcy in the latter half of 1960s. Deakin sought to utilise the 14 financial indicators offered by Beaver, and he also used the multivariate discri- minant analysis method in a similar way to Altman. This model predicted over $90 \%$ of corporate bankruptcies. The importance of the research consists in the fact that for the first time it showed the influence of the type of independent variables distribution. Deakin was the first to raise the topic of the necessity of normal distribution of independent variables in order to make a correct prediction. It had been previously ignored.

In subsequent years a series of research papers was published in which the authors stated their variations of the approach offered by Altman. J. Ohlson [8] was among these researchers. He added his own selection of variables into the series used by Altman and was the first to use the logistic regression method in bankruptcy prediction.

His model was comprised of nine variables. In comparison to the Z-score model, Ohlson included the company size logarithm, adjusted for inflation. This is due to the fact that small companies may be more exposed to bankruptcy risks. He also added an indicator showing the net profit change. Finally, there are two dummy variables in Ohlson's model which reference whether a company's liabilities exceed its assets and whether the company has been suffering losses for two years in a row.

Ohlson used a selection of 2,163 companies to test this method: 105 enterprises which went into bankruptcy in the period of 1970 to 1976 and 2,058 companies which did not encounter such difficulties. By some estimates, this method predicts companies' insolvency in more than $90 \%$ of cases.

The models described above divided enterprises into two groups: bankrupt ones and financially sound ones. L. Gilbert [9] offered an alternative methodology, which divides companies into three groups: reliable companies, failed and liquidated companies, and companies facing financial difficulties which carried on business. The selection for testing the model comprised 304 companies which demonstrated sustainable results between 1974 and 1983, the same number of companies experiencing financial difficulties within the same period and showing a negative net profit for three years, and 76 enterprises liquidated because of their inability to address their financial liabilities. The authors tested two models: the first one used a selection of bankrupt companies, and the second one used data about failed companies which carried on business. In both cases, the financial variables were taken from $\mathrm{E}$. Altman's [6] research.

The empirical verification of the methodology showed rather good results: the precision of the first model was $88.5 \%$, and the second one proved successful in $90.8 \%$ of cases. However, after a change in the selection of companies examined (the first model was tested using a selection of surviving companies and bankrupt companies and the second one using bankrupts and reliable companies) the predictive power of the models was reduced significantly, to less than $70 \%$.

The abovementioned approaches to the bankruptcy assessment may be placed into the numerical methods 
category. In spite of all the advantages of such models, they may yet leave out a series of qualitative characteristics which are difficult to measure in figures. As such, alternative models are sometimes used which approach financial indicator assessment methodologies from the subjective point of view.

For example, according to one such approach applied in the UK, the following indicators (among others) are assessed:

- a negative cash flow from operations over several consecutive periods;

- the amount of excessive overdue accounts payable;

- too frequent use of short-term financing to fund long-term projects;

- a constant deficit in terms of working capital;

- a steady tendency towards growth of debt in the capital structure.

On the one hand, such an approach takes into consideration the specific character of a certain enterprise and considers the array of factors which influence a company's financial standing. On the other hand, assessment of such parameters may be excessively subjective.

The last decade of the past century may be considered to have set off a fresh wave of papers dedicated to bankruptcy prediction, inasmuch as the researchers started to widely use new statistical and mathematical methods of prediction, in contrast to the first papers on this topic, which predominantly used approaches founded in discriminant analysis.

One of the methods which arguably diversified the researchers' mathematical apparatus was the neural network model - an artificial intelligence approach borrowed from neurobiology. One of the first studies in which the authors applied neural networks towards predicting company bankruptcy was the paper by M. Odom and R. Sharda [10]. In this article, the predictive capability of neural networks is compared to the most widespread method of bankruptcy prediction at the time - the multivariate discriminant analysis. The authors took Altman's papers as a basis of the company selection used for their research and added the data generated by the Monte Carlo method [6]. Variables used by Altman were taken as financial indicators. The authors used different approaches to neural network training and in all cases the results were more accurate than those obtained by the discriminant analysis approaches. The prediction accuracy of neural network models in various specifications reached up to $97 \%$. It is worth emphasising that the neural network models surpassed other methods in accuracy of classification of failed companies, which is considered to be the most complex and important challenge in the field. The authors concluded that that predictive accuracy may be even higher when using a greater number of appropriate exogenous variables.

The use of neural networks to predict bankruptcy was well received by the academic community, and much research was carried out which described various aspects of use of that method for predicting and identifying the various levels of companies' bankruptcy status.

The paper by G. Zhang et al. [11] made a noticeable contribution towards the understanding of the operating principle and the effectiveness of neural networks. The authors of that research compared the effectiveness of the forecasts obtained by using logistic regression and neural network approaches. Various specifications of neural networks were tested during the research and cross-validation of the results was conducted using different data selections. Finally, the authors conclude by extolling the supremacy of the neural networks approach to bankruptcy prediction and the classification of companies as financially sound or potential bankruptcy risks.

With an increase in the number of papers dedicated to bankruptcy, the idea put forth by S. Cho et al. [12] seems logical. The main point of their paper is that the authors tried to improve the quality of obtained forecasts by taking into account the results of several prediction methods at once, in this case the discriminant analysis, logistic regression, neural networks and decision tree approaches. The results of these four methods were the input data for the neural network, which made a forecast on the companies' financial standing. In spite of the unconventional nature of the approach, the authors of this research failed to significantly improve the forecast precision.

Among the latest papers on bankruptcy prediction the article by S. Lee and W. Choi [13] is of interest. They conducted research using a selection of Korean companies. They compared the accuracy of bankruptcy predictions of Korean companies from various economic sectors obtained using artificial neural networks and discriminant analysis. Independent variables were chosen out of 100 financial indicators by $t$-test and correlation analysis. The authors then concluded that neural network forecasts are more accurate than those obtained by the discriminant analysis approach. This result stems from the neural networks' ability to capture in a better way the nonlinear links between independent variables and the fact of bankruptcy. The authors also emphasise that the models built specially for a certain sector give better results than universal models intended for several sectors.

In the majority of papers on corporate bankruptcy, the target of research is American companies. The number of papers analysing companies from Russia and other countries with emerging markets is significantly lower. One among them is the research conducted by E. Fedorova, E. Gilenko and S. Dovzhenko [14]. That paper is distinguished by the fact that its authors applied a multi-stage procedure for the selection of independent variables out of a wide range of financial indicators. Among those indicators are many which have been used before in various bankruptcy prediction models (western and Russian ones), as well as indicators recommended by the Ministry of Finance of the Russian Federation. The selected indicators were used as input data for two specifications of neural networks. 
The paper by S.A. Gorbatkov, I.I. Beloliptsev, E.Yu. Makeeva [15] is also noteworthy. They compared the effectiveness of various sets of financial indicators in predicting bankruptcy in Russian companies which belong to the building sector using a neural networks model on the basis of the Bayesian approach.

The biggest number of articles considering corporate bankruptcy prediction in other developing economies is dedicated to Chinese companies, for example, see the research Y. Chen, L. Zhang and L. Zhang [16].

\section{Hybrid Algorithm}

This study presents a hybrid algorithm which is based upon the predictive effectiveness of the neural networks model [17]. However, the neural network does not by itself explain how the prediction result has been achieved, or which particular mechanism yields it. On the other hand, a fuzzy model of inference pertaining to the probability of bankruptcy risk uses human-understandable linguistic terms and explains which particular economic indicators (there are 16 of them in the model) reduce (or raise up) the bankruptcy risk for the analysed item. As per the stipulations of systems theory [1], an effective methodological combination induces a synergetic effect, which mutually strengthens the combined methods independently and in tandem.

The authors of the present study propose to divide the problem of solvency assessment of a large selection of enterprises into two sub-problems:

1) a group scoring assessment in the form of clustering (inside the generated clusters the enterprises are considered to be approximately uniform as regards their solvency);

2) an individual in-depth analysis of medium and large "problematic" enterprises following the results of clustering, (and alternatively, an analysis of individual enterprises carefully chosen from the clusters).

After solving both sub-problems, the obtained results are used in our hybrid comprehensive algorithm, which is tailored towards making decisions on lending procedure management, including the final stages of declaring the borrower bankrupt or debt restructuring.

Sub-problem 1 is solved using the universal neural network clusterisers [17] - Kohonen's self organising map. The resulting emergent effect is an opportunity for operational express-evaluation against a relatively large number of small borrowing companies.

Sub-problem 2 is solved by the unconventional hybrid fuzzy neural network algorithm described in detail below. The above-mentioned emergent effect produced by hybridisation consists of a combination of a rather high rate of correct detection of imminent bankruptcy (provided by the predictive neural networks model) and of a transparent mechanism of bankruptcy factor interpretations provided by the fuzzy description in regular terms (and applying Pospelov "grey" scale) $[3,18]$. Therewith, anticipatory actions may be used to control the bankruptcy factors.

In the proposed hybrid algorithm, the system concept of entropy reduction in the general system (obtained by combining rationally interacting subsystems in accordance with (1) ) is implemented as follows. The neural network predictive model of temporal series for each of the 16 indicators (factors) $\left\{x_{i}\right\}, i=\overline{1, n}$, with the added time factor $t \equiv x_{n+1}$, serves as subsystems of the bankruptcy risk assessment model $A_{1}$, while the fuzzy bankruptcy stages detection model serves as $A_{2}$. The following characteristics of the emergent (systemic) effect are present in and pertinent to the integrated system $\left(A_{1}, A_{2}\right)$ :

- the obtaining of fuzzy generalised assessments when detecting the bankruptcy stages of an analysed enterprise interpreted in the linguistic terms familiar to a lending expert;

- $\quad$ an opportunity to link the decisions taken in relation to the loan restructuring of the borrowing corporation to the generalised assessment of the bankruptcy stage.

This article considers two modifications of the hybrid algorithm (HA):

1) "a" - which is used in the fuzzy classifier of all indicators of $\left\{x_{i}\right\}, i=\overline{1, n}$ from the selected data;

2) "b" - which is the aggregation of all indicators into one generalised one $\mathrm{F}\left(x_{i}\right)$.

\section{Description of the Proposed Hybrid Algorithm: Modification "a"}

This version is based on a variables specification which is comprised of 16 indicators of $\left\{x_{i}\right\}, i=\overline{1, n}$ from the article by A.O. Nedosekin [3], which are easily calculated using publicly available accounting reports for PJSC.

Cluster 1 of the model variables specification - "profitability":

$R 1$ - profit margin (ratio of balance sheet profit to sales revenue and non-operating income, \%);

$R 2$ - return on assets (ratio of net profit to the average book value of assets, $\%$ per quarter);

$R 3$ - return on equity (ratio of net profit to the sum of capital and inventory (after deduction of shares repurchased), net of mission-oriented financing and receipts plus deferred revenue, $\%$ per quarter);

$R 4$ - product profitability (ratio of sales profit to sales revenue, \%);

$R 5$ - return on current assets (ratio of net profit to the average asset value, $\%$ per quarter).

Cluster 2 of the model variables specification - liquidity and solvency: 
L1 - quick liquidity ratio (ratio of current assets after deduction of inventory, value added tax on acquired assets and long-term receivables to short-term liabilities (except for deferred revenue), a non-dimensional value);

L2 - inventory cover ratio (ratio of company's own circulating assets, short-term loans and credits, and short-term liabilities, to the average inventory value, \%);

P1 - current liquidity ratio (ratio of current assets after deduction of long-term receivables to current liabilities (except for deferred revenue), a non-dimensional value).

Cluster 3 of the model variables specification - economic activity:

A2 - asset turnover (ratio of sales revenue after deduction of value added tax, excise duty and other liabilities to the average asset value, quarterly, a non-dimensional value);

A4 - payables turnover (ratio of sales revenue net of business and management expenses to average accounts payable, quarterly, a non-dimensional value);

A5 - accounts receivable turnover (ratio of sales revenue net of value added tax, excise duty and other liabilities, to accounts receivable as of the end of the reporting period after deduction of the founders' debts as regards contributions to the charter capital as of the end of the reporting period, quarterly, a non-dimensional value);

A6 - inventory turnover (ratio of the cost of price to the average inventory value, quarterly).

Cluster 4 of the model variables specification - financial stability:

F1 - leverage ratio (ratio of long-term liabilities plus short-term liabilities [except for deferred revenue] to capital and inventory [after deduction of shares repurchased] - mission-oriented financing and receipts added to deferred revenue, a non-dimensional value);

F2 - equity-assets ratio (ratio of capital and inventory [after deduction of shares repurchased] - mission-oriented financing and receipts added to deferred revenue - to the sum of non-current and current assets, a non-dimensional value);

F3 - inventory coverage with own circulating assets (ratio of own circulating assets to inventory, a non-dimensional value);

F4 - net fixed assets index (ratio of non-current assets added to accounts receivable to capital and inventory [after deduction of shares repurchased] - mission-oriented financing and receipts added to deferred revenue, a non-dimensional value).

Out of 16 introduced indicators, the values of F1 and F4 are inverted in relation to all other parameters because as the quantitative levels of these parameters grow the company's financial standing declines and the bankruptcy risk level grows. Consequently, in order to observe the precondition of unidirectionality of all parameters it is necessary to reconstitute $F 1$ and $F 4$ as follows:

$$
F 1 \rightarrow F \tilde{1}=1 / F 1 ; F 4 \rightarrow F \tilde{4}=1 / F 4
$$

In subsystem $A_{2}$ (i.e. the subsystem of the fuzzy model for identifying stages of bankruptcy), the authors used five levels ("granules") of fuzzy terms $T_{j}, j=\overline{1.5}$ of the bankruptcy risk indicator (these being $\mathrm{VH}$ - very high risk; HR - high risk; M - mean risk; L - low risk; and VL very low risk [e.g. solvent corporations]), in accordance with the pentascale (Fig. 1) which represents an uncontroversial classifier - the Pospelov "grey" scale $[1,18]$. This pentascale defines the rule of association (expression) of supports $\left\{u_{i}\right\}, i=\overline{1.16}$ with the considered term-set $\left\{T_{j i}\right\}$, where $u_{i}$ is a crisp number which represents a standardised value for indicators $x_{i}=R 1, R 2, \ldots, F 4$ : $u_{i}=\frac{x_{i}-x_{i . \min }}{x_{i . \max }-x_{i . \min }} ; u_{i} \in[0 ; 1]$.

The degree of an expert's confidence in the membership of support $u_{i}$ in the fuzzy term $T_{j i}$ is given by the "membership function" $\mu_{T_{j}}(u)$ laid off as ordinate in figure 1 . Trapezoid membership functions defined by four numbers $a_{1,} a_{2}, a_{3,} a_{4}$ were chosen.

In this case, all the neighbouring trapezia of the scale meet at the point of ordinate 0.5 . It is then seen that the increment of the power of one of the qualitative indicators is fraught with a corresponding decrease (at the same rate) of the neighbouring qualitative attribute, and at the point $\mu=0.5$ the maximum value for information fuzziness is achieved, and the neighbouring qualitative attributes within it have equal power (discernibility). In this case, the value of indicator $u_{i}$ belongs to a "lower" linguistic level (term). In order to specify the variation ranges and, consequently, the steepness of the membership functions, the four numbers $\left(a_{1,} a_{2}, a_{3}, a_{4}\right)$ in figure 1 were used.

Note the fact that there may be more complicated scales using 9 fuzzy terms with curvilinear trapezoid edges, as well as simpler scales with triangular membership functions. The authors of this article consider the pentascale in figure 1 as a "reasonable compromise" between the informativeness of the fuzzy classifier and its complexity.

Note the fact that for practical implementation of this hybrid algorithm, it is necessary to specify for each factor $x_{i}$ the range $\Delta x_{i}$ which defines the position of a corresponding fuzzy term $T_{j i},(i=\overline{1.16} ; j=\overline{1.5})$ in the $\mathrm{X}$-axis after normalisation (3).

Here we need expert estimates. 
Figure 1. Example of Pentascale

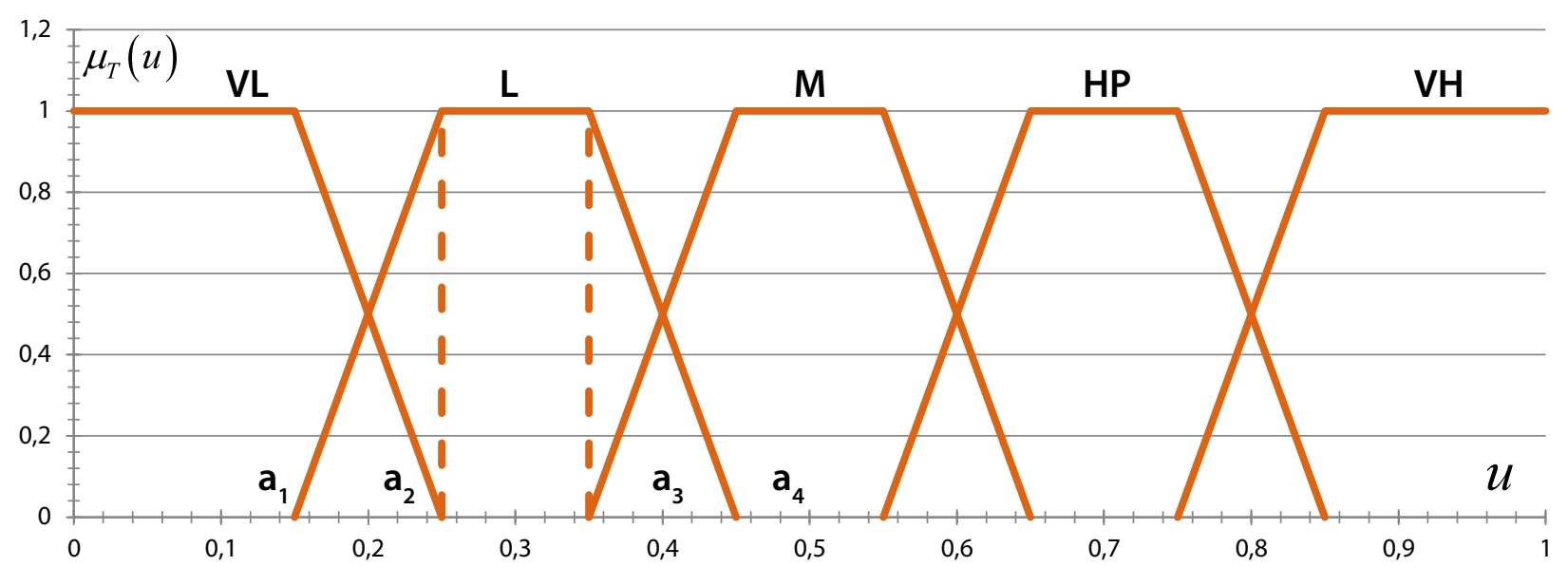

Table 1. Range of Values of Economic Indicators for Risk Level Groups

\begin{tabular}{|c|c|c|c|c|c|c|c|c|}
\hline Risk level group & $L 1$ & $L 2, \%$ & $P 1$ & $F 1$ & $F 2$ & $F 3$ & $F 4$ & $R 1, \%$ \\
\hline $\begin{array}{l}\text { Very high risk } \\
(\mathrm{VH})\end{array}$ & $0.1-0.2$ & $40-77$ & $0.1-0.4$ & $2.70-2.50$ & $0.25-0.31$ & $-2.00 \ldots-1.66$ & $1.60-1.51$ & $0-1$ \\
\hline High risk $(\mathrm{H})$ & $0.2-0.6$ & $77-144$ & $0.4-0.8$ & $2.50-1.70$ & $0.31-0.54$ & $-1.66 \ldots-0.33$ & $1.51-1.18$ & $1-5$ \\
\hline Mean risk (M) & $0.6-1.2$ & $144-267$ & $0.5-1.5$ & $1.70-1.17$ & $0.54-0.83$ & $-0.33 \ldots 0.92$ & $1.18-0.83$ & $5-16$ \\
\hline Low risk (L) & $1.2-2.0$ & $267-454$ & $1.5-2.4$ & $1.17-0.90$ & $0.83-0.93$ & $0.92-1.84$ & $0.83-0.56$ & $16-27$ \\
\hline Very low risk (VL) & $2.0-2.2$ & $454-580$ & $2.4-2.8$ & $0.90-0.50$ & $0.93-0.95$ & $1.84-3.50$ & $0.56-0.20$ & $27-30$ \\
\hline
\end{tabular}

End of table 1

$\begin{array}{lllllllll}\begin{array}{l}\text { Risk level } \\ \text { group }\end{array} & \begin{array}{l}R 2, \% \text { per } \\ \text { quarter }\end{array} & \begin{array}{l}R 3, \% \text { per } \\ \text { quarter }\end{array} & R 4, \% & \begin{array}{l}R 5, \% \text { per } \\ \text { quarter }\end{array} & \begin{array}{l}A 2, \\ \text { quarterly }\end{array} & \begin{array}{l}A 4, \\ \text { quarterly }\end{array} & \begin{array}{l}A 5, \\ \text { quarterly }\end{array} & \begin{array}{l}A 6, \\ \text { quarterly }\end{array}\end{array}$

\begin{tabular}{|c|c|c|c|c|c|c|c|c|}
\hline $\begin{array}{l}\text { Very high } \\
\text { risk (VH) }\end{array}$ & $-3.00 \ldots 2.50$ & $-4.00 \ldots 3.33$ & $0-1$ & $-5.00 \ldots-4.42$ & $0.06-0.08$ & $0.40-0.50$ & $0.60-0.70$ & $1.0-1.3$ \\
\hline $\begin{array}{l}\text { High risk } \\
\text { (H) }\end{array}$ & $-2.50 \ldots-0.50$ & $-3.33 \ldots-0.66$ & $1-5$ & $-4.42 \ldots-0.58$ & $0.08-0.15$ & $0.50-0.90$ & $0.70-1.10$ & $1.3-2.3$ \\
\hline $\begin{array}{l}\text { Mean risk } \\
(\mathrm{M})\end{array}$ & $-0.50-\ldots+1.57$ & $-0.66 \ldots 3.17$ & $5-15$ & $-0.58 \ldots 2.58$ & $0.15-0.24$ & $0.90-1.54$ & $1.10-1.74$ & $2.3-3.5$ \\
\hline Low risk (L) & $1.57-4.34$ & $3.17-7.84$ & $15-27$ & $2.58-10.27$ & $0.24-0.29$ & $1.54-2.07$ & $1.74-2.07$ & $3.5-5.5$ \\
\hline $\begin{array}{l}\text { Very low } \\
\text { risk (VL) }\end{array}$ & $4.34-8.00$ & $7.84-20.00$ & $27-46$ & $10.27-18.00$ & $0.29-0.58$ & $2.07-5.80$ & $2.07-5.80$ & $5.5-15$ \\
\hline
\end{tabular}

The authors used the convenient expert table 1 from [3] where an expert committee comprised of leading specialists involved in finance and credit was engaged in order to apply the pentascale in the classification of objects, and table 1 was developed for practical use.

The method of use of table 1 is very simple: if historical records exist for the abovementioned 16 indicators $x_{i}(t)$, then temporal series are calculated and predicted values are defined for all 16 indicators $\left\{x_{j, 0}\right\}, j=\overline{1.16}$ for the planned period $t=t_{0}$ using the universal neural networks approximator [17]. In quantitative estimations we used the multi-layer perception (MLP) neural network with the back propagation (BP) learning algorithm. 
For important objects of financing, the model was reinforced with the Bayesian neural networks regularisation algorithm. In this algorithm, the network architecture and activation functions of hidden layers of neurons [1] were varied using the Bayes group.

The predicted values $\left\{x_{j, 0}\right\}, j=\overline{1.16}$ are inserted in table 1 , and the value of fuzzy terms levels are defined for the present object, i.e. the "bankruptcy image" is recognised.

\section{Results of Quantitative Estimations of the Proposed Algorithm of Version "a" Accompanied by an Analysis of all 16 Indicators}

The example in table 2 is an approximation and prediction fragment of explicative variables $\boldsymbol{x}_{\boldsymbol{i}}(16$ criteria) for three quarters to come, for a large agricultural enterprise in the Sterlitamak District of the Republic of Bashkortostan (reference number 30 in the selection of 30 enterprises) [1].
In table 3, a part of the calculations is shown when a borrowing company gets into the range of financial indicators values which correspond to each value defined by experts (the intervals of getting into the range are colourised). As one can see in table 3 , analysed enterprise number 30 pertains to the class of low bankruptcy risk, which has been proven by experimental observations in the manufacturing environment by an interdistrict tax inspectorate.

Let us remark that tables 2 and 3 help to "recognise the image" of advancing bankruptcy of an analysed corporation rather quickly and, what is important, they help to identify the indicators which need improvement using the terms an analyst understands. In the given example it is L2 (inventory cover ratio). Consequently, in this paper's hybrid algorithm of bankruptcy risk assessment, the operation of the fuzzy classifier is indeed an effective addition to the neural network. This is a positive characteristic feature of modification "a" of the hybrid algorithm.

However, modification "a" has a drawback: it does not take into account the interaction of indicators with each other in case of the fuzzy bankruptcy risk classification which occurs in actual practice.

Table 2. Fragment of Prediction of Explicative Variables for Enterprise 30

\begin{tabular}{|c|c|c|c|c|c|c|c|c|c|}
\hline Year, enterprise 30 & Quarter & $L 1$ & $L 2, \%$ & $P 1$ & $F 1$ & $F 2$ & F3 & $F 4$ & $A 6$ \\
\hline 2006_03 & 1 & 0.402 & 264.99 & 2.563 & 0.751 & 0.799 & 1.35 & 0.509 & 1.555 \\
\hline 2006_09 & 2 & 0.67 & 286.48 & 2.900 & 0.998 & 0.652 & 1.95 & 0.491 & 1.344 \\
\hline 2006_12 & 3 & 0.63 & 278.15 & 2.838 & 1.385 & 0.722 & 1.485 & 0.484 & 7.835 \\
\hline 2007_03 & 4 & 0.21 & 269.74 & 2.593 & 0.833 & 0.75 & 1.397 & 0.481 & 1.490 \\
\hline 2007_06 & 5 & 0.42 & 278.18 & 2.642 & 1.222 & 0.74 & 1.282 & 0.553 & 1.331 \\
\hline 2007_09 & 6 & 0.24 & 232.58 & 2.781 & 0.872 & 0.679 & 1.241 & 0.54 & 1.491 \\
\hline 2007_12 & 7 & 0.236 & 278.25 & 2.120 & 1.327 & 0.754 & 1.182 & 0.508 & 13.976 \\
\hline 2008_03 & 8 & 0.26 & 244.72 & 2.147 & 0.761 & 0.793 & 1.147 & 0.525 & 1.145 \\
\hline 2008_06 & 9 & 0.311 & 257.79 & 2.922 & 0,624 & 0.702 & 1.178 & 0.529 & 2.364 \\
\hline 2008_09 & 10 & 0.3 & 279.95 & 2.316 & 1.272 & 0.729 & 1.728 & 0.499 & 2.214 \\
\hline $2008 \_12$ & 11 & 0.28 & 270.49 & 2.548 & 0.953 & 0.789 & 0.205 & 0.52 & 11.649 \\
\hline 2009_03 & 12 & 0.121 & 225.49 & 2.2824 & 0.713 & 0.862 & 1.155 & 0.518 & 0.749 \\
\hline \multirow{3}{*}{$\begin{array}{l}\text { Predicted values } \\
\text { calculated using the } \\
\text { neural networks } \\
\text { models of temporal } \\
\text { series }\end{array}$} & 13 & 0.192 & 248.440 & 2.328 & 0.720 & 0.842 & 1.279 & 0.506 & 5.011 \\
\hline & 14 & 0.179 & 246.061 & 2.293 & 0.646 & 0.867 & 1.269 & 0.519 & 5.100 \\
\hline & 15 & 0.168 & 243.628 & 2.258 & 0.569 & 0.892 & 1.270 & 0.513 & 5.189 \\
\hline
\end{tabular}

The abovementioned drawback of modification "a" of the hybrid algorithm is eliminated when it is complemented with aggregation of all considered indicators into one complex indicator $\mathrm{F}\left(x_{i}\right), i=\overline{1.16}$. As a result, we have modification " $\mathrm{b}$ " of the hybrid algorithm. 


\section{Description of Modification "b" Algorithm}

Table 3. Interpretation of the Predicted Values of Indicators (membership intervals for the $13^{\text {th }}$ quarter of analysed enterprise 30 are highlighted in a dark colour)

\begin{tabular}{|c|c|c|c|c|c|}
\hline Risk level group & Very high risk & High risk & Mean risk & Low risk & Very low risk \\
\hline$L 1$ & $0.1-0.2$ & $0.2-0.6$ & $0.6-1.2$ & $1.2-2.0$ & $2.0-2.2$ \\
\hline$L 2, \%$ & $40-77$ & $77-144$ & $144-267$ & $267-454$ & $454-580$ \\
\hline$P 1$ & $0.1-0.4$ & $0.4-0.8$ & $0.8-1.5$ & $1.5-2.4$ & $2.4-2.8$ \\
\hline$F 1$ & $2.70-2.50$ & $2.50-1.70$ & $1.70-1.17$ & $1.17-0.90$ & $0.90-0.50$ \\
\hline$F 2$ & $0.25-0.31$ & $0.31-0.54$ & $0.54-0.83$ & $0.83-0.93$ & $0.93-0.95$ \\
\hline$F 3$ & $-2.00 \ldots-1.66$ & $-1.66 \ldots-0.33$ & $-0.33 \ldots 0.92$ & $0.92-1.84$ & $1.84-3.50$ \\
\hline$F 4$ & $1.60-1.51$ & $1.51-1.18$ & $1.18-0.83$ & $0.83-0.56$ & $0.56-0.20$ \\
\hline$R 1, \%$ & $0-1$ & $1-5$ & $5-16$ & $15-27$ & $27-46$ \\
\hline$R 2, \%$ per quarter & $-3.00 \ldots-2.50$ & $-2.50 \ldots-0.50$ & $-0.50 \ldots+1.57$ & $1.57-4.34$ & $4.34-8.00$ \\
\hline$R 3, \%$ per quarter & $-4.00 \ldots-3.33$ & $-3.33 \ldots-0.66$ & $-0.66 \ldots+3.17$ & $3.17-7.84$ & $7.84-20.00$ \\
\hline$R 4, \%$ & $0-1$ & $1-5$ & $5-15$ & $15-27$ & $27-46$ \\
\hline$R 5, \%$ per quarter & $-5.00 \ldots-4.42$ & $-4.42 \ldots-0.58$ & $-0.58 \ldots .2 .58$ & $2.58-10.27$ & $10.27-18.00$ \\
\hline$A 2$, quarterly & $0.06-0.08$ & $0.08-0.15$ & $0.15-0.24$ & $0.24-0.29$ & $0.29-0.58$ \\
\hline$A 4$, quarterly & $0.40-0.50$ & $0.50-0.90$ & $0.90-1.54$ & $1.54-2.07$ & $2.07-5.80$ \\
\hline$A 5$, quarterly & $0.60-0.70$ & $0.70-1.10$ & $1.10-1.74$ & $1.74-2.27$ & $2.27-5.80$ \\
\hline$A 6$, quarterly & $1.0-1.3$ & $1.3-2.3$ & $2.3-3.5$ & $3.5-5.5$ & $5.5-15$ \\
\hline
\end{tabular}

The indicators in the fuzzy classifier using the pentascale (fig. 1) may be aggregated in two ways:

1) a double matrix-folding (i.e. a convolutional approach) method [3].

2) Mumdani's fuzzy inference method [19].

The double matrix-folding method resultant uses formula (4):

$$
\Phi=\sum_{i=1}^{n} p_{i}\left(\sum_{j=1}^{5} \alpha_{j} \mu_{i j}\left(x_{i}\right)\right), i=\overline{1.16} ; j=\overline{1.5}
$$

Here weighting factors $\alpha_{j}$ of the inner sum according to index $j$ are the so-called "junctures", i.e. the midpoints of the upper bounds of trapezia projected to the transversal axis of supports. For example, the junctures in fig. 1 form a vector

$$
\vec{\alpha}=(0.075 ; 0.3 ; 0.5 ; 0.7 ; 0.925) \text {. }
$$

As a result of the fuzzy classification one can match each point in the definition interval of the supporting linguistic

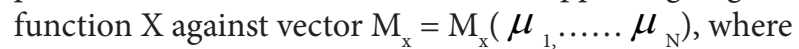
$N$ is the number of scale granules (in the described case $N$ $=5$ ); $\mu_{j}$ is the value of the level of the $j$-th membership function. Herewith for Pospelov "grey" scale the following condition is fulfilled

$$
\sum_{j=1}^{n} \mu_{\mathrm{j}}=1
$$

For the outer sum in (4) as per index $i$ the weighting factors $\left\{p_{i}\right\}, i=\overline{1,16}$ are Fishburn's or Saaty's weighting factors, which take into account the preferences of indicators arranged in order of decreasing preference; $\mu_{i j}\left(x_{i}\right)$ is the value of the membership function of the $j$-th qualitative level against the current value of the $i$-th indicator.

Fishburn's weighting scheme implements OWA (Ordered Weighted Averaging) - Yager operator.

In Fishburn's scheme, preferences in the hierarchy scheme change by 1 when passing from one fixed hierarchical level to another. The weights decrease according to the weight arithmetic progression rule:

$$
p_{i}=\frac{2(n-i+1)}{n+1}, i=1,2, \ldots \text {. }
$$

If there are no preferences among the indicators, the following corresponds to the indifferent weighting system:

$p_{i}=1 / n i=1,2, \ldots, n$. 
In other words, according to Fishburn, preferences are expressed as a decrease by one of the rational fraction numerator of the weighting factor of a weaker alternative. In order to define a set of Fishburn's weights for a mixed system of preferences (along with the preferences' indifference ratios which comprise the system), it is necessary to define rational fractions numerators $\boldsymbol{r}_{i}$ using the following recursion scheme:

$$
p_{i-1}=\left\{\begin{array}{c}
p_{i}, x_{i-1} \approx x_{i} \\
p_{i+1}, x_{i-1}>x_{i} ; p_{n}=1 ; i=n \ldots 2,
\end{array}\right.
$$

where $\approx-$ the equivalence sign; $>-$ the preference sign. Then, the total value of obtained numerators is the common denominator of Fishburn's fractions:

$$
K=\sum_{i=1}^{n} p_{i}
$$

The value of the composite indicator $\mathrm{F}\left(x_{i}\right)$ obtained in accordance with (4) is further interpreted by the pentascale, i.e. affiliation of the value of $\mathrm{F}\left(x_{i}\right)$ with one of some fuzzy terms is defined.

Due to the limited size of the present article, the indicators' aggregation algorithm according to Mamdani's fuzzy inference method is not described here. It can be found in detail in [19].

\section{Conclusions}

The authors proposed an unconventional algorithm for diagnosing corporate bankruptcy stages on the basis of a system-wide law of an integrated system $\left(A_{1}\right.$ and $\left.A_{2}\right)$ entropy decrease in contrast to the sum of entropies of subsystems being united. Herewith, subsystem $A_{1}$ is represented by the neural networks predictive model of bankruptcy indicators (16 indicators by A.O. Nedosekin), and subsystem $\mathrm{A}_{2}$ is represented by the fuzzy model of bankruptcy stages detection. The emergent (systemic) effect achieved in the integrated system $\left(A_{1}, A_{2}\right)$ is manifested in the unification of the significant predictive power of neural networks with an illustrative interpretation of the obtained results in the form of linguistic terms which are understandable for analysts (formulated by way of fuzzy sets ).

The offered algorithm was tried out on a series of experimental observations for 30 agricultural enterprises of Sterlitamak District of the Republic of Bashkortostan.

The offered algorithm gives a rather quick assessment of the borrowing company's financial standing with a controlled probability. In our example with the probability of 0.94 , the bankruptcy risk assessment of enterprise 30 is in the range of "low - very low".

A valuable characteristic of this approach is the wide range of indicators which are part of the assessment. Taking into consideration their interrelation, which is typical for an economic unit, we get a rather broad picture of the assessment.
The offered algorithm imposes none of the strict requirements on the database which are present in the classical least squares method used in regression analysis. In the various least squares method modifications which change the abovementioned requirements very slightly, they are called 'prerequisites' of the least squares method. In particular, a prerequisite of the least squares method which is difficult to implement is the hypothesis of the 'normal law of distribution of computational accidental errors' over the model.

The focus on the neural networks method, free from such prerequisites, has its own drawback in our hybrid algorithm. In this case, there is no possibility to assess the adequacy of the obtained model based on a verification of statistical hypotheses about fulfillment of the prerequisites of the least squares method. However according to computing experiments, the model adequacy assessment may be founded on the basis of Bayesian approach [1]. As such, the regularisation of the proposed predictive model for each of the 16 bankruptcy indicators is achieved.

\section{References}

1) Gorbatkov S.A., Polupanov D.V. Makeev E.Yu., Biryukov A.N. Methodological basis for the development of neural network models of economic objects in conditions of uncertainty. Moscow: "Ekonomicheskaya gazeta" Publ.; 2012. 494 p. (In Russ.).

2) Tikhonov A.N., Arsenin V.Ya. Methods for solving incorrect problems. M.: Nauka; 1986. 288 p. (In Russ.).

3) Nedosekin A.O. Comprehensive corporate bankruptcy risk assessment based on fuzzy descriptions. URL: http://www.ifel.ru/br7/3.pdf (accessed on 15.12.2013). (In Russ.).

4) Prangishvili I.I. System approach and system-wide patterns. Moscow: SINTEG; 2000. 522 p. (In Russ.).

5) Beaver W. Financial ratios as predictors of failure. Journal of Accounting Research. 1966;4:71-111. DOI: 10.2307/2490171

6) Altman E.I., Financial ratios, discriminant analysis and the prediction of corporate bankruptcy. The Journal of Finance. 1968;23(4):589-609. DOI: $10.2307 / 2978933$

7) Deakin E.B. A discriminant analysis of predictors of business failure. Journal of Accounting Research. 1972;10(1):167-179. DOI: 10.2307/2490225

8) Ohlson J.A. Financial ratios and the probabilistic prediction of bankruptcy. Journal of Accounting Research. 1980;18(1):109-131. DOI: 10.2307/2490395

9) Gilbert L.R., Krishnagopal M., Schwartz K.B. Predicting bankruptcy for firm in financial distress. Journal of Business Finance \& Accounting. 1990;17(1):161-171. DOI: 10.1111/j.1468-5957.1990. tb00555.x 
10) Odom M., Sharda R. A neural network model for bankruptcy prediction. In: 1990 IJCNN Int. Joint Conference on Neural Networks (San Diego, CA, 17-21 June 1990). Piscataway Township, NJ: IEEE; 1990:163-168. DOI: 10.1109/IJCNN.1990.137710

11) Zhang G., Hu M.Y., Patuwo B.E., Indro D.C. Artificial neural networks in bankruptcy prediction: General framework and cross-validation analysis. European Journal of Operational Research. 1999;116(1):16-32. DOI: 10.1016/S0377-2217(98)00051-4

12) Cho S., Kim J., Bae J.K. An integrative model with subject weight based on neural network learning for bankruptcy prediction. Expert Systems with Applications. 2009;36(1):403-410. DOI: 10.1016/j. eswa.2007.09.060

13) Lee S., Choi W.S. A multi-industry bankruptcy prediction model using back-propagation neural network and multivariate discriminant analysis. Expert Systems with Applications. 2013;40(8):29412946. DOI: 10.1016/j.eswa.2012.12.009

14) Fedorova E., Gilenko E., Dovzhenko S. Bankruptcy prediction for Russian companies: Application of combined classifiers. Expert Systems with Applications. 2013;40(18):7285-7293. DOI: 10.1016/j. eswa.2013.07.032

15) Gorbatkov S.A., Beloliptsev I.I., Makeeva E.Yu. Selection of the system of economic indicators for diagnostics and prediction of bankruptcies based on neural network Bayesian approach. Vestnik Finansovogo universiteta $=$ Bulletin of the Financial University. 2013;(4):50-61. (In Russ.).

16) Chen Y., Zhang L., Zhang L. Financial distress prediction for Chinese listed manufacturing companies. Procedia Computer Science. 2013;17:678686. DOI: $10.1016 /$ j.procs.2013.05.088

17) Haykin S. Neural networks: A comprehensive foundation. $2^{\text {nd }}$ ed. Transl. from Eng. Moscow: Williams; 2006. 1104 p. (In Russ.).

18) Pospelov D.S. "Grey" and/or "black and white" scale. Applied Ergonomics. Special issue "Reflexive processes”. 1994;(1):29-33. (In Russ.).

19) Borisov V.V., Kruglov V.V., Fedulov A.S. Fuzzy models and networks. Moscow: Goryachaya liniya-Telekom; 2007. 284 p. (In Russ.). 